\title{
A PRÁTICA PROFISSIONAL DO CURSO TÉCNICO EM ALIMENTOS DA UEMA: POTENCIALIZANDO O AMBIENTE VIRTUAL DE APRENDIZAGEM
}

\author{
Ilka Marcia Ribeiro de Souza Serra; Eliza Flora Muniz Araujo \\ ilka.tt@gmail.com \\ Universidade Estadual do Maranhao \\ DOI: 10.15628/rbept.2018.7016 \\ Artigo submetido em jan/2018 e aceito em mar/2018
}

\begin{abstract}
RESUMO
As novas tecnologias e a internet a cada dia abrem novas possibilidades e desafios pedagógicos para o processo ensino-aprendizagem. Hoje é possível socializar o desenvolvimento da Prática Profissional num Ambiente Virtual de Aprendizagem de forma colaborativa. A Prática Profissional vivenciada no Curso Técnico em Alimentos da Universidade Estadual do Maranhão se apresenta como um componente desafiador e facilitador da aquisição de conhecimentos e desenvolvimento de habilidades, fazendo com que os trabalhadores possam enfrentar cada vez mais situações profissionais dinâmicas e complexas. O objetivo principal desta pesquisa foi identificar a aplicabilidade das estratégias metodológicas adotadas na Prática Profissional, incluindo o uso das ferramentas tecnológicas para a eficácia do processo ensino-aprendizagem, e, consequentemente, potencializar a vivência da prática com vistas a atuação eficiente do aprendiz no mundo do trabalho. $\mathrm{O}$ estudo realizado utilizou metodologia de natureza quali-quantitativa com alunos e tutores do Curso Técnico em Alimentos, ofertado na modalidade a distância, na forma subsequente. Os resultados apresentados tanto por parte dos alunos quanto dos tutores, apontaram a importância do Ambiente Virtual de Aprendizagem como uma ferramenta inovadora, que propicia a interação das pessoas não apenas em um ambiente físico, mas também on-line, contribuindo dessa forma para o fortalecimento das relações interpessoais.
\end{abstract}

Palavras-Chave: Educação a Distância, Ambiente Virtual de Aprendizagem, Prática Profissional, Recursos Tecnológicos.

\section{THE PROFESSIONAL PRACTICE OF UEMA'S TECHNICAL COURSE IN FOOD: MAXIMIZING THE VIRTUAL LEARNING ENVIRONMENT}

\begin{abstract}
Every day new technologies and the internet open up new possibilities and pedagogical challenges for the teaching-learning process. Today it is possible to socialize the development of the Professional Practice in a Virtual Learning Environment, in a collaborative manner. The Professional Practice experienced in the Technical Course in Food of the Maranhão State University is presented as a challenging as well as a facilitating component of knowledge acquisition and skills development, which workers may increasingly face in dynamic and complex professional situations. The main objective of this research was to identify the applicability of methodological strategies adopted in Professional Practice, including the use of technological tools for the effectiveness of the teaching-learning process and, therefore, to
\end{abstract}


enhance the experience of the practice to improve the efficient performance of the apprentice in the world of work. This study used a methodology of qualitative-quantitative nature with students and tutors of the Technical Course in Food, offered in distance modality, in the subsequent form. The results presented regarding both students and tutors, pointed out the importance of the Virtual Learning Environment as an innovative tool, which facilitates the interaction of people not only in a physical environment but also online, in this way, contributing to the strengthening of interpersonal relationships.

Keywords: Distance Education, Virtual Learning Environment, Professional Practice, Technological Resources.

\section{INTRODUÇÃO}

Com o acelerado avanço das tecnologias digitais, do computador e da internet, nestas últimas décadas, que de forma muito perspicaz vai se incorporando cada vez mais às atividades humanas, nos leva ao reconhecimento de que estamos inseridos numa sociedade baseada na informação. Uma sociedade dinâmica, que vive em constante mudança, onde até mesmo as noções de tempo e espaço se alteram constantemente.

A tecnologia vem introduzindo profundas mudanças em todos os setores da sociedade, na economia, na forma de nos comunicarmos e relacionarmos com os outros, especialmente, na maneira de como aprendemos. Consequência disso, é a necessidade de haver pessoas mais qualificadas para assumirem os postos de trabalho, ou seja, com conhecimentos e habilidades requeridas nesta nova era digital (SANTOS, 2016, p. 55).

É evidente que as Tecnologias da Informação e Comunicação (TIC) e as mídias interativas estão provocando mudanças no modo de ser e agir das pessoas, vislumbrando uma nova forma de fazer educação. Nesse sentido, surge um novo paradigma educacional a partir da evolução de instrumentos ligados à tecnologia da informação - a Educação a Distância (EaD). "Para educar, é necessário quebrar barreiras, reduzir distâncias. [...] Esse é o caminho para uma educação transformadora e sintonizada com as demandas da sociedade pós-moderna, uma Educação SEM Distância". (TORI, 2017, p 33).

Muito embora entenda-se que a tecnologia tem a sua importância, esta, não pode ser vista como o principal fator. É importante compreender que as políticas públicas educacionais envolvem um conjunto de pressupostos teóricos-metodológicos que nos remetem a reflexões críticas dos diferentes contextos sociais. "Por isso, os complexos contextos em que se inscrevem os projetos e programas de EaD obrigam-se a revisar suas diretrizes didático-pedagógicas, notadamente no momento de transição de 
paradigmas que caracteriza o final do século XX e o início do século XXI". (OLIVEIRA, 2006, p. 75).

A busca pela inserção das novas tecnologias na educação, não invalida os métodos tradicionais de ensino, mas, não se pode deixar de reconhecer que avanços tecnológicos evidenciam novos determinantes, especialmente, no que diz respeito às noções de tempo e espaço. Nesse sentido, o principal desafio da EaD, é justamente vencer as barreiras de espaço e tempo, simultaneamente, envolvendo diferentes meios de comunicação e tornando-se acessível, com qualidade, para um contingente significativo de pessoas, que por diferentes motivos não tem, ou tiveram acesso aos meios convencionais de ensino.

O estudo teve como objetivo identificar a aplicabilidade das estratégicas metodológicas adotadas no Curso Técnico em Alimentos da Universidade Estadual do Maranhão - UEMA, na modalidade a distância, como opção tecnológica para socialização da Prática Profissional, por meio do Ambiente Virtual de Aprendizagem (AVA), incluindo o uso de recursos tecnológicos inovadores.

A pesquisa utilizou metodologia de natureza quali-qualitativa com a participação de alunos e tutores do Curso Técnico em Alimentos, da Universidade Estadual do Maranhão (UEMA), ofertado na modalidade a Distância, trazendo à evidência novas demandas impostas pelo processo de globalização e inserção de tecnologias no cenário educacional, revelando possibilidades e oportunidades decorridas da formação técnica profissional.

No contexto da pesquisa ressalta-se a importância da educação a distância $(\mathrm{EaD})$, enquanto modalidade de ensino que oportuniza a mediação do conhecimento por meio das ferramentas tecnológicas, para oferecer educação a setores ou grupos da população que, por motivos diversos, passam pelo enfrentamento da escassez de oferta e acesso a serviços educativos regulares. Dessa forma, torna-se importante a reflexão sobre a relação entre as TIC e as práticas pedagógicas. Nessa direção, os resultados apontam a importância de potencializar o desenvolvimento da Prática Profissional num Ambiente Virtual de Aprendizagem (AVA), de forma colaborativa, tornando possível a interação e troca de experiências em diferentes tempos e espaços de vivência.

\section{RESSIGNIFICANDO A PRÁTICA PROFISSIONAL}

\subsection{A Prática Profissional}

A Lei de Diretrizes e Bases da Educação Nacional no 9.394/96 estabeleceu uma nova concepção de ensino voltado para o desenvolvimento 
de competências cognitivas e profissionais, numa perspectiva de educação vinculada "ao mundo do trabalho e à prática social" conforme estabelece o Artigo $1^{\circ}$ da LDB:

As diretrizes curriculares para a educação profissional e técnica de nível médio devem retomar a educação profissional não adestradora, não fragmentada. Devem dar aos jovens e adultos trabalhadores, na interação com a sociedade, os elementos necessários para discutir, além de entender, a ciência que move os processos produtivos e as relações sociais geradas com o sistema produtivo. (PACHECO, 2012 p.10).

Com base nessa concepção, cabe ressalvar que as diretrizes curriculares nacionais para o ensino médio e a educação profissional tratam com clareza sobre a vinculação entre a educação escolar e a prática social do educando, em especial no que se refere ao mundo do trabalho, princípio já

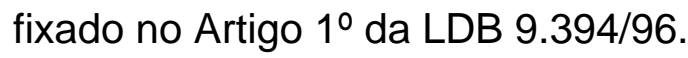

Sem dúvida, o desenvolvimento das novas tecnologias de comunicação e informação está impactando as formas de aprender e ensinar. $\mathrm{Na}$ sociedade atual, convive-se com novas exigências do mercado de trabalho, novas formas de ser e viver socialmente, fazendo repensar sobre 0 papel da educação. Segundo Bates (2016, p. 57): "A partir de uma perspectiva de ensino, o maior impacto tende a ser em professores e alunos das áreas técnicas e profissionais, em que o componente de conhecimento de habilidades, a princípio, sobretudo manuais, está se expandindo rapidamente".

E, no bojo dessa reflexão, a educação a distância se apresenta como um campo de pesquisa e reflexão importante, considerando as barreiras que é capaz de transpor e as ferramentas disponibilizadas para facilitar o aprendizado, como se posiciona Tori, (2017, p.33):

Hoje, as tecnologias de redução de distâncias já estão incorporadas em nosso cotidiano. Para as novas gerações o estranho é ficar sentado em uma sala, offine, sem os recursos digitais que já se tornaram extensões de seus corpos e mentes, sem interatividade. [...] Para educar, é necessário quebrar barreiras, reduzir distâncias. [...] Esse é o caminho para uma educação transformadora e sintonizada com as demandas da sociedade pós-moderna, uma Educação SEM Distância.

Nessa perspectiva, a Universidade Estadual do Maranhão estabeleceu como diretrizes para os cursos técnicos na modalidade a distância, que a Prática Profissional possibilite a contextualização do aprendizado dos estudantes, oportunizando a integração teoria/prática, articulando 
conhecimentos, habilidades e atitudes para 0 desenvolvimento das competências necessárias ao exercício profissional, conforme preconizado no Manual "Referenciais para os Cursos Técnicos da Universidade Estadual do Maranhão - 2013".

Dessa forma, a concepção da Prática Profissional adotada nos cursos técnicos da UEMA, objetiva propiciar vivências das diferentes situações práticas de estudo e trabalho conforme o Parágrafo Único da Resolução ํo 6, de 20 de setembro de 2012, que assim determina: "Quando se tratar de profissões regulamentadas, o perfil profissional de conclusão deve considerar e contemplar as atribuições funcionais previstas na legislação específica referente ao exercício profissional fiscalizado". (BRASIL, 2012).

Em tal contexto, a prática encontra-se configurada como atividade para formação profissional, entendida como ato educativo de caráter interdisciplinar, integrando a teoria com a prática no processo de ensino e aprendizagem, conforme trata o Artigo 21 da Resolução ํo 6, de 20 de setembro de 2012:

A prática na Educação Profissional compreende diferentes situações de vivência, aprendizagem e trabalho, como experimentos e atividades específicas em ambientes especiais, tais como laboratórios, oficinas, empresas pedagógicas, ateliês e outros, bem como investigação sobre atividades profissionais, projetos de pesquisa e / ou intervenção, visitas técnicas, simulações, observações e outras.

É com essa compreensão que a Prática Profissional estabelecida no Projeto Pedagógico do Curso considera para efeito da profissionalização, as atividades de aprendizagem social, profissional e cultural proporcionadas ao estudante pela participação em situações reais de vida e trabalho, bem como atividades de extensão mediante a participação do estudante em empreendimentos ou em projetos. Portanto, a Prática Profissional busca oportunizar a atualização teórico-metodológica no que diz respeito à troca de experiências, conhecimentos e aperfeiçoamento de técnicas.

Assim sendo, destaca-se a importância das atividades práticas para a formação de sujeitos atuantes, de modo que tal ato educativo não se restrinja ao "saber fazer", mas que possibilite a formação integral dos indivíduos oportunizando espaços de construções e descobertas no decorrer do curso. Saber "o que fazer e como fazer" também são essenciais e não se dissociam da dimensão teórica e político social da educação (CANDAU, 2012). Messe sentido, a autora ainda complementa: 
as especializações do setor educacional onde estão presentes os profissionais que planejam e, contudo, não executam nem avaliam e profissionais que executam, sem ter planejado (CANDAU, 2012, p. 32).

A Prática Profissional se configura não como situações ou momentos distintos do curso, mas como uma metodologia de ensino que contextualiza e põe em ação o aprendizado. De acordo com Preti (2005, p. 81): "Espaço seria, então, esse locus onde são construídos os significados sociais, culturais, a partir dos processos de interlocução, de compartilhamento, de diálogo, de troca entre sujeitos relacionais, situados historicamente".

Dessa forma, a Prática Profissional engloba um campo vasto para atuação dos profissionais em formação, pois não se limita meramente ao encaminhamento do estudante para atuação em uma empresa e ou instituição. Esta se desenvolve durante todo o curso, cuja carga horária a ser cumprida obedece ao respectivo Plano de Curso, bem como aos Planos de Atividades, em coerência com os itinerários de profissionalização.

Como processo metodológico os cursos técnicos da UEMA, desenvolvem diferentes atividades práticas focadas nos objetivos de cada profissão, conforme apresentado na Figura a seguir:

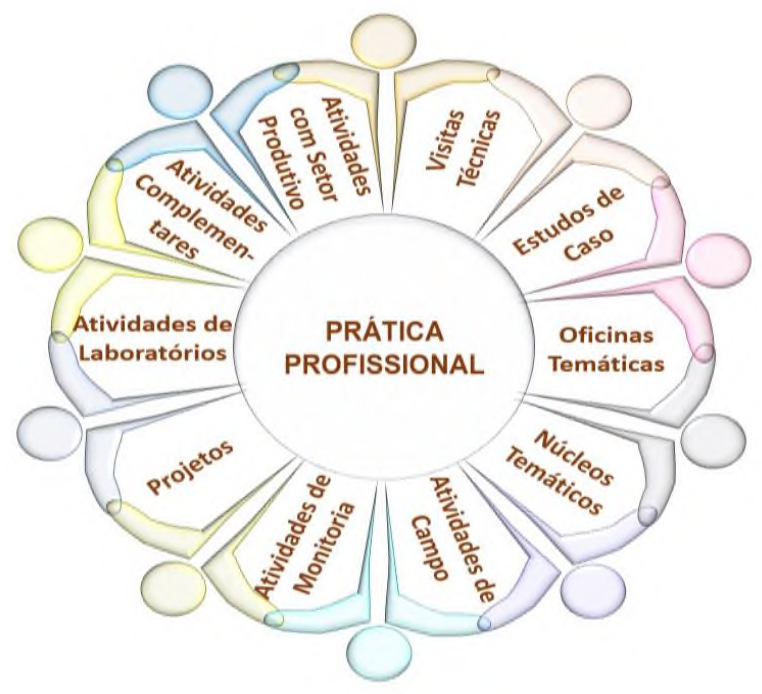

Figura 1: Visão geral das atividades da prática profissional na UEMA

Nessa perspectiva, as ações práticas resultam tanto da ação do estudante sobre a realidade como da mediação das TIC e atuação dos professores e tutores na concretização de tais atividades. Portanto, a Prática Profissional vivenciada nos cursos Técnicos da Universidade Estadual do Maranhão se apresenta como um componente desafiador e facilitador da aquisição de conhecimentos e desenvolvimento de habilidades para que os 
trabalhadores possam enfrentar cada vez mais situações profissionais dinâmicas e complexas.

\title{
3 POTENCIALIZANDO O AMBIENTE VIRTUAL DE APRENDIZAGEM
}

\subsection{A Sala de Aula Virtual}

As Tecnologias de Informação e Comunicação (TIC) tem disponibilizado meios que contribuem de forma expressiva para dinamizar os processos de ensinar e aprender, acrescentando ferramentas importantes para o desenvolvimento de qualquer projeto educativo. $\mathrm{Na} E A D$, as salas virtuais são providas de ferramentas que facilitam a comunicação síncrona ou assíncrona, potencializando a troca de saberes e a construção de conhecimentos de maneira interativa, de forma que qualquer pessoa, independentemente do tempo e do espaço, possa se tornar agente de sua aprendizagem.

A despeito disso Aretio (1994, p. 39) ressalta que:

\begin{abstract}
A EaD é um sistema tecnológico de comunicação bidirecional, que pode ser massivo e que substitui a interação pessoal na sala de aula, de professor e estudante, como meio preferencial de ensino, pela ação sistemática e conjunta de diversos recursos didáticos e pelo apoio de uma organização e Tutoria que propiciam a aprendizagem independente e flexível dos estudantes.
\end{abstract}

Com o advento da Internet e das redes de comunicação em tempo real, surgem novos e importantes espaços para o processo de ensinoaprendizagem, transformando e ampliando o que se fazia na sala de aula (MORAN, 2004, p.1). A tecnologia, a interatividade e o desenvolvimento da autonomia do aluno resultam numa nova realidade de concepção de aprendizagem colaborativa, a partir das comunidades virtuais e o suporte de ferramentas tecnológicas desenvolvidas para a EaD.

Nos cursos ofertados na modalidade a distância a principal ferramenta é o Ambiente Virtual de Aprendizagem (AVA), onde ocorre os processos comunicacionais, aprendizagem e avaliação do aluno. Para Kenski (2003, p. 55) os AVAs, de um modo geral, podem ser definidos como:

Local em que se partilham fluxos e mensagens para a difusão dos saberes, o ambiente virtual de aprendizagem se constrói com base no estímulo à realização de atividades colaborativas, em que 0 
aluno não se sinta só, isolado, dialogando apenas com a máquina ou com o instrutor, também virtual.

A UEMA utiliza o Moodle (acrônimo de Modular Object-Orienteded Dynamic Learning Encrionment) como plataforma de aprendizagem para os cursos a distância, na versão 2.8. O Moodle é um software livre, que pode ser modificado e aperfeiçoado por quem tiver interesse em utilizá-lo. Beline \& Salvi (2011. p.4) o definem assim:

O Moodle é um software para produzir e gerenciar atividades educacionais baseadas na Internet e/ou em redes locais. É um projeto de desenvolvimento contínuo projetado para apoiar o socialconstrutivismo educacional. Conjuga um sistema de administração de atividades educacionais com um pacote de software desenhado para ajudar os educadores a obter alto padrão de qualidade em atividades educacionais on-line que desenvolvem.

Nessa perspectiva, o AVA assume grande relevância neste estudo, enquanto espaço planejado para abrigar o Curso Técnico em Alimentos, constituindo-se numa inovadora ferramenta tecnológica, mediadora do processo de ensino-aprendizagem. Assim sendo, esse espaço virtual deve ser um ambiente agradável e acolhedor que promova a participação, o debate e a interação entre os participantes do curso. Para Almeida (2003, p. 4) AVAs "[...] são sistemas computacionais disponíveis na internet, destinados ao suporte de atividades mediadas pelas tecnologias de informação e comunicação".

O ambiente virtual de aprendizagem possibilita aos professores e tutores o acompanhamento dos seus alunos. Estes por sua vez podem realizar as atividades que foram programadas, debater ideias e acessar 0 conteúdo das disciplinas, e ainda acompanhar o seu avanço através do relatório de atividades.

A figuras a seguir, retratam a sala virtual do Curso Técnico em Alimentos da UEMA, com as ferramentas tecnológicas e recursos didáticos utilizados para potencializar as interações, estimulando o contato e a participação dos alunos e tutores. 


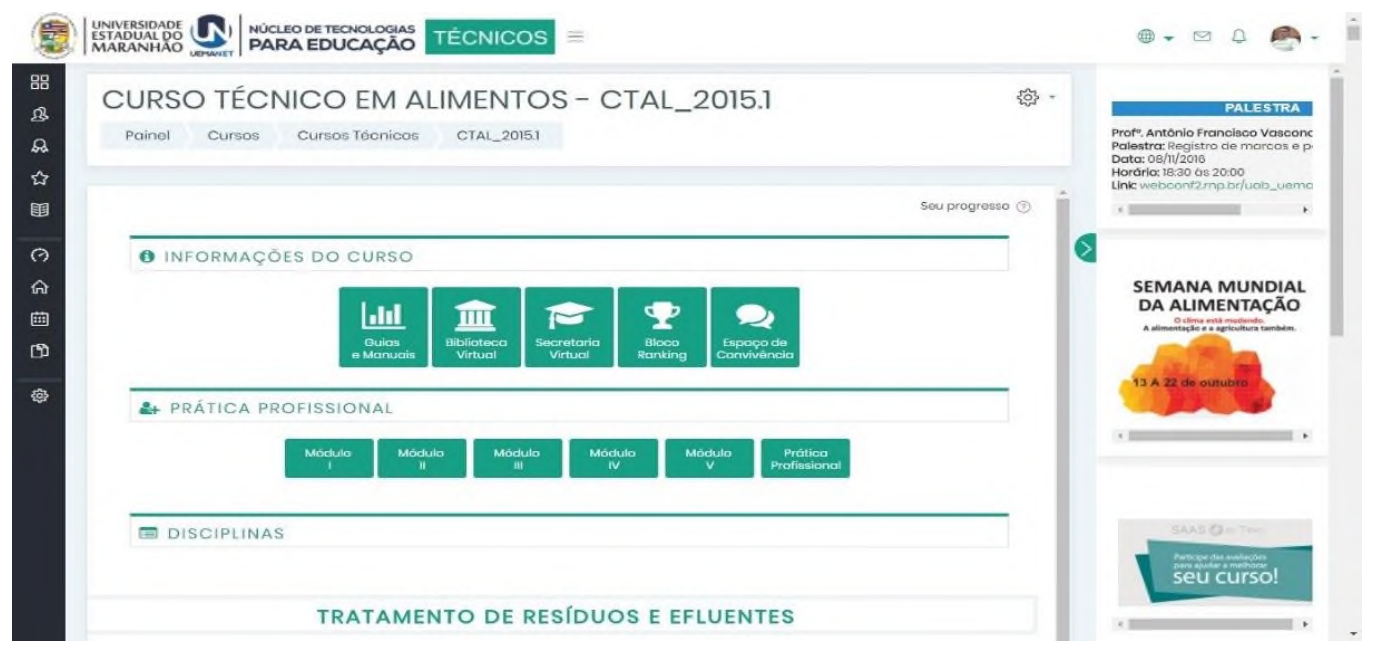

Figura 2: Print da sala de aula virtual - ferramentas tecnológicas

De acordo com Soares $(2011$, p. 43) "a potencialização da construção do conhecimento se dá mediante a inserção e utilização de diferentes mídias para fluxos de comunicação dentro do Ambiente Virtual". Para o referido autor, a interface em si não é o foco, mas como esta propõe e acolhe a comunicação pedagógica.
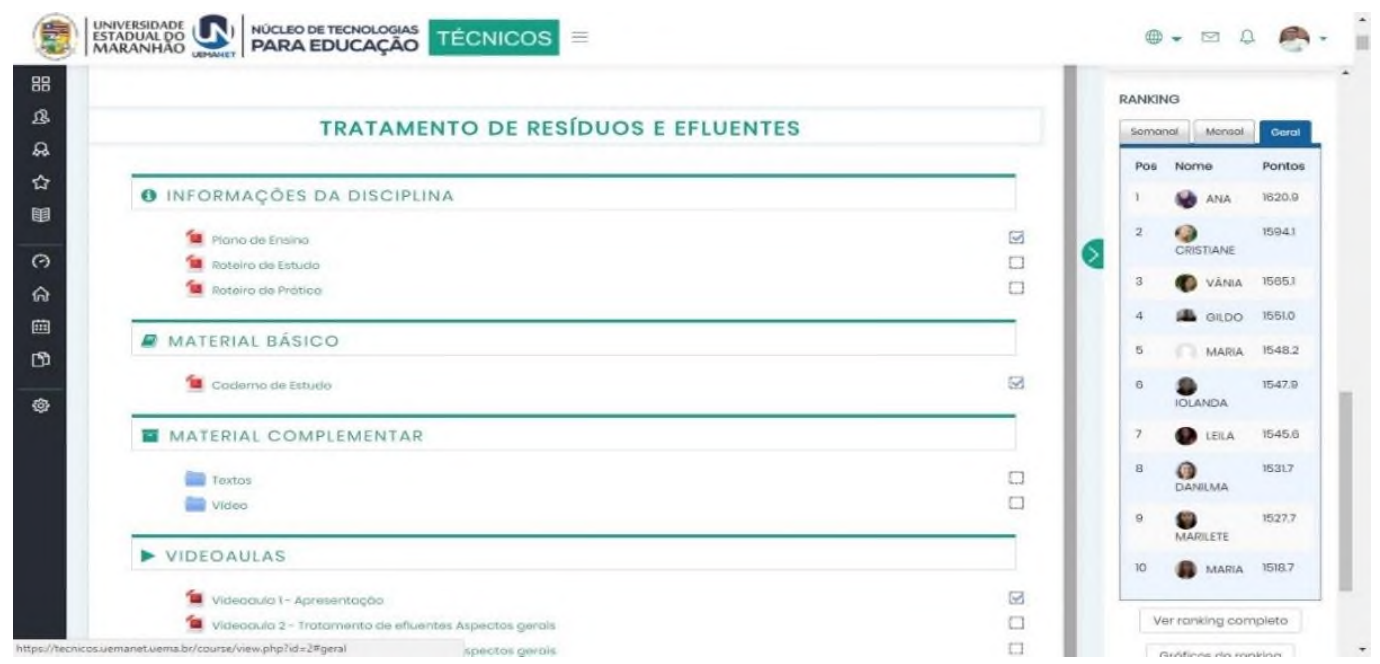

Figura 3: Print da sala de aula virtual - recursos didáticos

Os print acima apresentados dão ideia da organização do ambiente virtual, ou seja, as possibilidades geradas pelas ferramentas tecnológicas. Tal organização permite o compartilhamento de dados e informações, introduzindo novas formas de comunicação e socialização do saber, configurando assim, diferentes maneiras de construir o conhecimento. 


\section{METODOLOGIA}

Esta pesquisa caracteriza-se como um estudo de caso, vez que investiga um contexto específico de uma sala virtual, ou seja, a socialização da prática profissional do Curso Técnico em Alimentos, na modalidade a distância, no Ambiente Virtual da Universidade Estadual do Maranhão.

A metodologia utilizada baseou-se nas abordagens qualitativa e quantitativa, pertinentes ao estudo realizado. Segundo Preti (2010), desenvolver uma pesquisa não é somente acumular dados e quantifica-los, mas, especialmente, analisar causas e efeitos, de forma contextualizada no tempo e no espaço, amparada por uma concepção sistêmica. "[...] esses dados são considerados mais ricos, globais e reais" (PRETTI, 2010, p. 590). Assim, se refere o autor sobre a adoção do uso simultâneo da abordagem quali-quantitativa.

A referida pesquisa foi realizada na turma do Curso Técnico em Alimentos, com predominância descritiva, cujas informações coletadas encontram-se apresentadas, principalmente, em forma de textos, onde se buscou analisa-las com toda sua riqueza, respeitando a forma de registro ou transcrição original. Nesse sentido, Cervo, Bervian e Silva (2007, p. 46) indicam a pesquisa descritiva como "um método que possui dimensão de observação e proximidade com o fenômeno e, a partir daí, propõem identificar os problemas de pesquisa e orientar a análise".

A pesquisa foi realizada no período de março a junho de 2016, por meio da aplicação de um questionário com os alunos (via e-mail) e observação no Ambiente Virtual de Aprendizagem. A entrevista com os tutores, teve como foco as atividades destinadas à socialização da Prática Profissional. Cabe registrar que o Curso Técnico em Alimentos, nessa oferta, teve uma turma única, pertencente ao Polo de Apoio Presencial Paulo VI. A referida turma, no ato da investigação, possuía 21 alunos e dois tutores (um presencial e um a distância,). É importante registrar que a turma iniciou com 30 alunos, mas no decorrer do curso ocorreram cinco desistências e duas reprovações.

A escolha por essa turma, teve como motivação, constatar como em um curso com significativo peso de atividades práticas poderia ser desenvolvido numa plataforma tecnológica, e, notadamente, como as tecnologias auxiliariam no processo de aprendizagem do aluno. Vale observar que nessa ocasião, a UEMA desenvolvia mais oito cursos técnicos em diferentes Polos, distribuídos em diferentes municípios do Estado do Maranhão. O período de realização da pesquisa ocorreu em vários momentos das atividades da Prática Profissional, mais especificamente, durante o quarto 
e penúltimo módulo do curso, vez que nesse período as atividades da prática já se encontram mais consolidadas.

Cabe observar, que a organização da matriz curricular é constituída por cinco Módulos, sendo o primeiro considerado básico, composto pelas disciplinas do Núcleo Comum. A partir do segundo Módulo iniciam-se as atividades da Prática Profissional, inclusive com certificação intermediaria.

Como demonstrado anteriormente (Figura 3), 0 ambiente de aprendizagem é rico de possibilidades, permitindo um conjunto de atividades como: fórum, café virtual, wiki, chat, diário de bordo, blogs, tarefas, testes objetivos, estudo de caso, provas e outros, bem como os materiais didáticos disponíveis que contribuem para o enriquecimento dos estudos. "Dessa forma, é preciso compreender a educação on-line como [...] um conjunto de ações de ensino e aprendizagem ou atos de currículo mediados por interfaces digitais que potencializam práticas comunicacionais interativas e hipertextuais" (SANTOS, 2010, p. 37) Para este autor, o AVA funciona como uma organização viva, propiciando a interação do homem com os objetos, num processo complexo que se auto organiza na dialogicidade de suas redes e conexões (SANTOS, 2010, p. 39).

No que diz respeito à experiência profissional e nível de formação, os dois tutores investigados já tiveram atuação em EaD e possuíam nível superior: um graduado em Tecnologia de Alimentos e o outro licenciado em Química. Essa constatação é importante, considerando ser a formação um dos principais critérios requeridos na seleção para o exercício da tutoria na UEMA. Além da experiência com tutoria, o edital de seleção exige que a formação deva ser compatível com a área do curso. Possuíam, também, curso de formação continuada em mediação tecnológica para o exercício na EaD. A formação acadêmica e complementar do tutor, relacionada ao desenvolvimento de competências essenciais à atuação na educação a distância é importante para a construção do diálogo virtual com o aluno (BERNARDINO, 2011, p. 4).

Participaram da pesquisa, dois tutores (100\%) e 08 alunos (38\%). No que diz respeito ao quantitativo de alunos a previsão era de 11 participantes, no entanto, três não deram devolutivas. A coleta das informações com os alunos foi feita por meio de um questionário, enviado por e-mail, contendo 12 questões, sendo 10 objetivas e duas abertas, que versaram sobre a obtenção do perfil acadêmico e de outras questões mais voltadas para as dificuldades e/ou facilidades das ferramentas disponibilizadas no ambiente virtual para o aprimoramento da Prática Profissional. Além da aplicação do questionário, foram utilizados com o consentimento da Coordenação Pedagógica do curso, dados brutos do AVA/ Moodle, provenientes da observação das atividades postadas pelos alunos com a mediação dos tutores, especialmente, durante a sistematização de algumas atividades relativas à Pratica Profissional, onde pode-se examinar a participação dos alunos e tutores. 
Quanto aos tutores, por ser um número reduzido, foi realizada uma entrevista virtual, cujas questões tiveram o objetivo de compreender como estes percebiam as potencialidades geradas pelo AVA, no contexto da Prática Profissional, tendo em vista o processo de aprendizagem, considerando o uso das ferramentas de comunicação, materiais didáticos, atividades interativas, suporte de internet, processos avaliativos e o seu papel enquanto mediador da aprendizagem.

\section{RESULTADOS E DISCUSSOES}

As experiências práticas nos cursos técnicos da UEMA têm oportunizado a articulação entre teoria e prática, e, ensino e aprendizagem possibilitando o desenvolvimento do senso crítico na perspectiva do enfrentamento dos desafios postos pelo mundo do trabalho. Assim, a socialização da prática profissional no Ambiente Virtual possibilita maior reflexão e a construção da identidade profissional.

Destaca-se, nesse contexto, a importância da socialização das práticas por meio das ferramentas tecnológicas, no intuito de democratizar as experiências e a construção de conhecimentos, contribuindo para a formação de mão de obra qualificada que atenda as aspirações pessoais e profissionais. Nesse sentido, Bittar (2011) coloca que a integração da tecnologia digital é de suma importância no processo de aprendizagem do aluno, desde que lhe possibilite compreender, ter acesso e explorar diferentes aspectos do saber em cena (BITTAR, 2011, p. 159).

Para compreender melhor a dinâmica da socialização da Prática Profissional no AVA, fez-se o recorte da primeira etapa de uma atividade sobre produção de alimentos que aconteceu no Laboratório de Química, de forma presencial, e depois postada no ambiente para continuidade das discussões, questionamentos e aprofundamento teórico. 


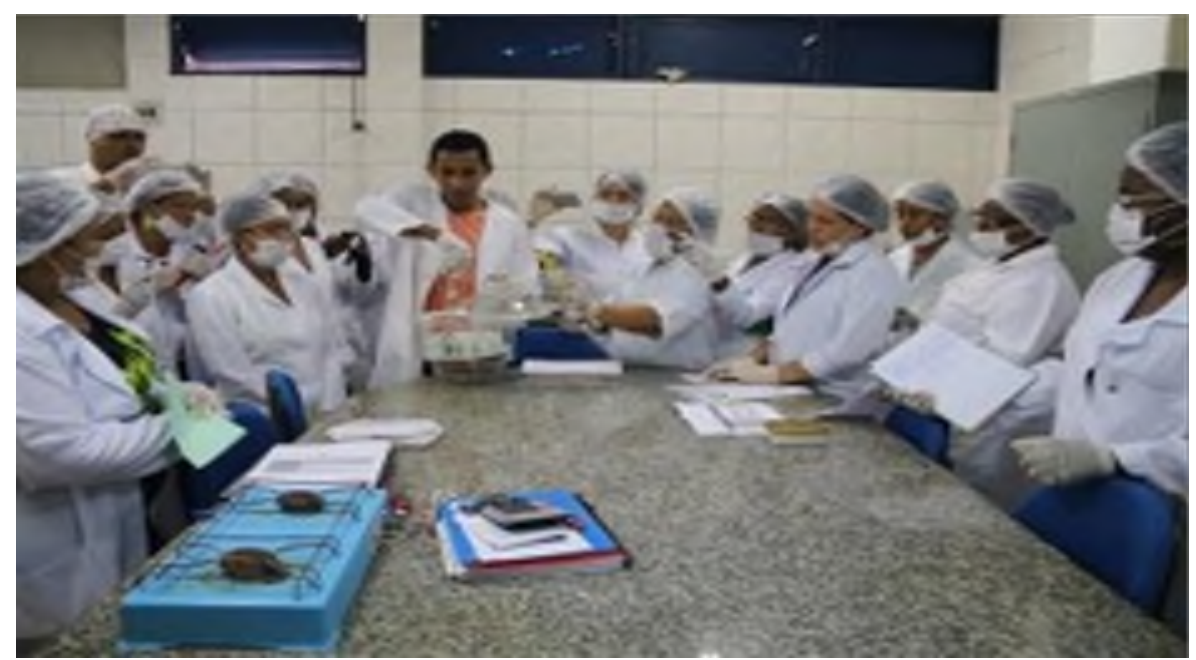

Figura: 4 - Atividade realizada em laboratório e socializada na sala virtual.

Essa atividade constituiu-se objeto de análise e discussão sob a orientação do tutor a distância. A temática desenvolvida nessa atividade diz respeito à produção de alimentos, onde puderam discutir teoricamente os conteúdos e observar os procedimentos relativos à tecnologia de panificação, massas e confeitaria.

Após essa etapa, ou seja, várias aulas sobre o conteúdo dessa temática, os alunos tiveram a oportunidade de exercitarem in loco os conhecimentos adquiridos durante todo o Módulo, em algumas empresas, como ocorreu nesse caso, realizada numa Panificadora, com 0 acompanhamento do Tutor Presencial.

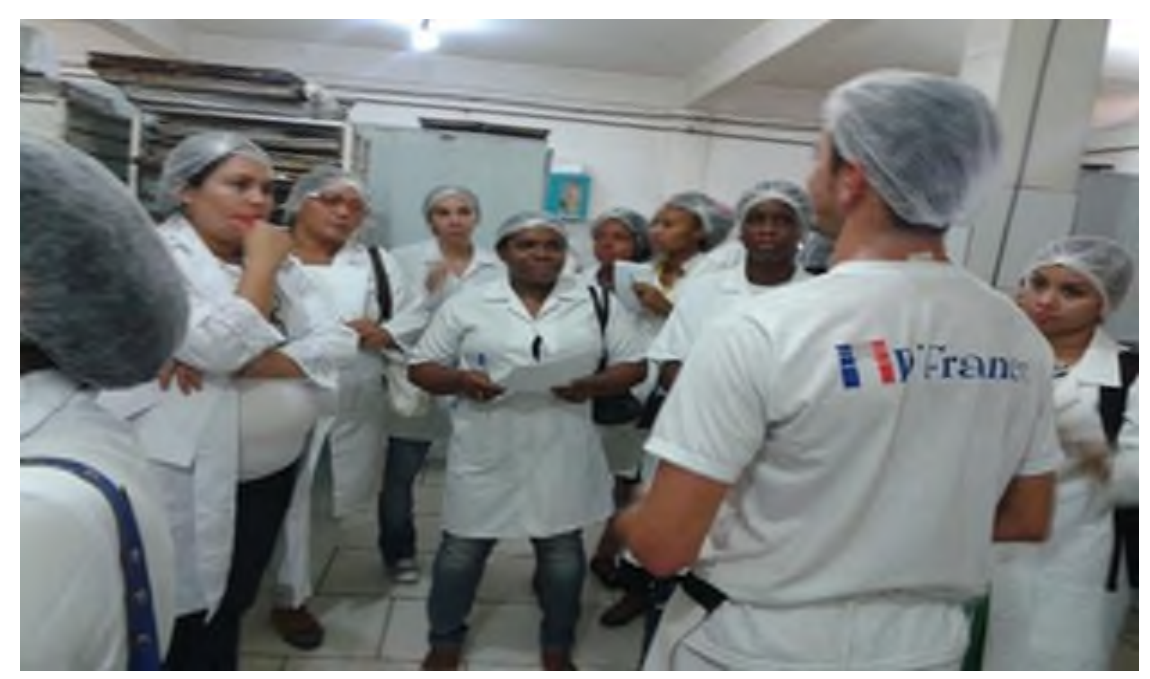

Figura 5: Desenvolvimento da Prática Profissional numa Panificadora

Após cada uma dessas etapas, as atividades foram socializadas no AVA, onde desenvolveram diferentes tarefas: vídeo aula para 
aprofundamento do assunto, chat para discussões sobre os diferentes testes e métodos aplicados aos alimentos em laboratório, análise sensorial dos alimentos, fórum tira dúvidas, e muitas outras.

Das entrevistas realizadas com os tutores pode-se selecionar algumas falas as quais apontam para as indagações que se propôs investigar. Para resguardar a identidade dos mesmos vamos identificá-los como Tutor Presencial e Tutor a Distância. Vejamos alguns relatos:

"Durante o curso realizei várias experiências em laboratório com os meus alunos e que depois foram socializadas no AVA. Exemplo disso foram as atividades práticas realizadas a partir de uma visita técnica numa Agroindústria. Com base nessa visita, foi aberto um fórum para o compartilhamento das experiências vivenciadas. Esse espaço de discussão permitiu a comparação das opiniões emitidas pelos alunos e, a partir daí fizeram uma releitura da experiência, acrescentando novas contribuições e aprofundaram os conhecimentos discutindo de que forma os resíduos podem afetar a população se não forem descartados de forma correta" (Tutor Presencial).

"O AVA é um espaço educativo de suma importância para o compartilhamento do conhecimento, vez que os alunos realizam suas práticas nos laboratórios e empresas e depois trazem para a sala virtual as experiências vivenciadas em diferentes espaços laborais. Posso citar a construção de uma Cartilha Educativa feita coletivamente pelos alunos com a participação do tutor presencial, cujo conteúdo abordou orientações sobre boas práticas de alimentação e o aproveitamento adequado dos produtos. Essa atividade possibilitou a interação entre os alunos, o professor da disciplina e os tutores presencial e a distância, com momentos muito ricos de interação no ambiente" (Tutor a Distância).

"Na ocasião, os alunos aprenderam na prática, sobre o Programa de Boas Práticas de Fabricação e as etapas de implantação do programa, a fim de produzir alimentos com qualidade sanitária e em conformidade com a legislação, bem como, sobre os métodos de controle de qualidade e os princípios das boas práticas de fabricação na indústria de alimentos. Essa atividade foi vivenciada tanto presencial quanto virtual, sendo que uma complementou a outra. $\mathrm{Na}$ parte virtual a gente percebe que os alunos ficam mais soltos, 
mais à vontade, e colocam mais suas dúvidas." (Tutor Presencial).

"O momento da atividade em campo teve o propósito de aperfeiçoar a prática profissional dos estudantes que se preparam para ingressar no mercado de trabalho, aprofundando, assim, seus conhecimentos e a compreensão in loco, relativos aos conteúdos estudados academicamente. Foi uma visita muito produtiva, houve uma integração positiva entre os participantes, principalmente pela troca de experiências entre alunos e os profissionais da área". As discussões desta atividade se prolongaram na sala virtual, gerando o compartilhamento de saberes, o que considero um momento muito rico de aprendizagem tanto para os alunos como para nós que aprendemos muito também" (Tutor a Distância).

Fica evidente na fala dos tutores que o ambiente virtual é muito importante para socialização do conhecimento e que a parte realizada no AVA, por existir vários recursos, contribui significativamente para exercitar as atividades, dirimir dúvidas e aprofundar conteúdos e práticas. Além dos depoimentos resultantes das entrevistas com os tutores pode-se ainda, extrair alguns elementos de suas falas que reforçam a importância da EaD:

- $\quad$ O aproveitamento e valorização do saber que o aluno traz da sua experiência de vida, fazendo conexão com o conhecimento apreendido é muito importante quando se trabalha com educação a distância;

- $\quad$ No que diz respeito a EaD o incentivo ao processo de aprender com o seu próprio desenvolvimento, autonomia para construir o seu conhecimento, e, aprender na interação com os seus pares são aspectos de grande relevância;

- A oportunidade de construir conhecimentos significativos, a partir de reflexão crítica, com base em vivências práticas, tanto em laboratórios e oficinas quanto no AVA só enriquecem o aprendizado de quem estuda na modalidade a distância;

- As possibilidades de troca de experiências, fortalecendo as relações entre os alunos, tutores e professores, bem como a transformação das informações em conhecimento, são questões muito bem trabalhadas na modalidade EaD.

No que diz respeito ao questionário aplicado com os alunos, as respostas foram tabuladas e agrupadas, selecionando-se apenas três, ou seja, aquelas que respondem com mais clareza a funcionalidade do AVA: 
"As atividades realizadas no AVA trazem grandes ajudas, porque podemos trocar ideias com os colegas e com os tutores on-line, tirar dúvidas e treinar mais nossos conhecimentos. Além disso, podemos ver e rever várias vezes os conteúdos e as práticas desenvolvidas. A gente cria grupos com pessoas que muitas vezes nem conhecemos presencialmente, mas, que se tornam nossos colegas no ambiente, é muito legal".

"Tenho certeza que as atividades desenvolvidas no AVA são de grande utilidade para o meu desempenho profissional, pois além de reforçar os meus conhecimentos, me deu mais segurança na execução das atividades práticas, me dando a chance de discutir com várias pessoas e tirar minhas dúvidas. Os fóruns ajudam muito no processo de discussão, assim como os chats. As vezes o que atrapalha um pouco é queda de internet".

"O uso das ferramentas tecnológicas auxilia muito no reforço das atividades da Prática Profissional. A gente usa vários recursos e ainda pode interagir com os colegas e com os tutores. Considero muito importante $o$ trabalho que se faz no AVA, contribui para o nosso crescimento profissional. Fazemos várias atividades para cada disciplina, além das constantes avaliações. No começo tive algumas dificuldades, mas com a ajuda dos tutores e de alguns colegas consegui superar e hoje já dou suporte a outros colegas".

Os resultados apontaram tanto por parte dos alunos quanto dos tutores, a importância dessa ferramenta, como uma alternativa inovadora, pois, possibilita corrigir dificuldades ocorridas durante o processo de aprendizagem, principalmente no que diz respeito à articulação dos conhecimentos teóricos e sua aplicabilidade na prática.

Os resultados apresentados tanto por parte dos alunos quanto dos tutores, apontaram a importância do Ambiente Virtual de Aprendizagem como uma ferramenta inovadora, visto que, contribui para o estabelecimento das relações interpessoais, enquanto aprendizes em uma sociedade cada vez mais orientada pela capacidade dos indivíduos de transformarem dados em informações e informações em conhecimento. 


\section{CONCLUSÕES}

Essas possibilidades advindas do Ambiente Virtual despertaram na UEMA uma nova forma de estabelecer o elo entre a formação teórica do estudante e a prática profissional, oportunizando a socialização das experiências de campo, do exercício do trabalho em equipe e da interação com os profissionais da área, no decorrer do curso. Portanto, percebeu-se que o AVA constitui-se um espaço de aprendizagem viável, onde os estudantes e tutores se comunicam utilizando materiais interativos on line, laboratórios virtuais, softwares de simulações e modelagens (animações), blogs, wikis, listas de discussões, fóruns, chats, e-mail e outros.

É importante ressaltar que dada as possibilidades da internet é possível socializar o desenvolvimento da Prática Profissional num Ambiente Virtual de Aprendizagem, de forma colaborativa, com alunos e tutores, inclusive em diferentes Polos de Apoio Presencial, simultaneamente, tornando possível transpor as dificuldades de tempo e espaço e potencializar interação e troca de experiências.

Conforme evidenciado nas falas dos tutores sobre as estratégias desenvolvidas na superação das dificuldades dos alunos, percebe-se muita satisfação, inclusive, sobre as possibilidades permitidas pelo AVA. Além disso, demonstraram estar cientes que o trabalho da Prática Profissional não se dá só na Empresa, mas também no ambiente virtual, e, para tanto, exige a articulação constante dos diferentes profissionais envolvidos nessa ação, na perspectiva da construção de um trabalho pedagógico eficiente.

Ainda nesse contexto, contatou-se a necessidade de ter um Polo de Apoio Presencial bem estruturado, com computadores disponíveis para os alunos e internet de boa qualidade. Alia-se a isso, a formação dos tutores na área do curso e formações continuadas para acompanhar as disciplinas, e, especialmente, as atividades da Prática Profissional que exige conhecimentos e habilidades para orientar e acompanhar o aluno nesse exercício.

Dessa forma, chegou-se ao entendimento de que as tecnologias digitais são ferramentas importantes e podem contribuir significativamente para a melhoria do processo ensino-aprendizagem. E que a conjugação das ferramentas tecnológicas e os recursos convencionais podem ser potencializados desde que haja um bom planejamento, suporte tecnológico adequado e profissionais preparados para a condução de todo o processo.

\section{REFERÊNCIAS}

ALMEIDA, M. E. B. de. Tecnologia e educação a distância: abordagens e contribuições dos ambientes digitais e interativos de aprendizagem. In: 26a 
REUNIÃO ANUAL DA ASSOCIAÇÃO NACIONAL DE PÓS-GRADUAÇÃO E PESQUISA EM EDUCAÇÃO - ANPED. Poços de Caldas, 2003.

ARETIO, Lorenzo Garcia. Educación a distancia hoy. Madrid: UNED, 1994.

BATES, Tony. Educar na Era Digital: design, ensino e aprendizagem. Tradução de Teaching in a Digital Age: guidelines for designing teaching and learning de Anthony Willian (Tony) Bates. Artesanato Educacional: São Paulo, 2016 (Coleção Tecnologia Educacional).

BERNARDINO, H.S. A tutoria na EaD: os papéis, as competências e a relevância do tutor. Paidéi@ - Revista Científica de Educação a Distância. v. 2, n. 4, jul. 2011. Disponível em < https://www.researchgate.net/publication/293824876 >. Acesso em: 22 dez. 2017.

BITTAR, M. A abordagem instrumental para o estudo da integração da tecnologia na prática pedagógica do professor de matemática. Educar em Revista. Curitiba, v.1, p.157 - 171, 2011.

BELINE, Willian; SALVI, Rosana Figueiredo. EAD e Software Livre - desafios para a transformação social. In: CIQEAD - Congresso Internacional de Qualidade em EAD, São Leopoldo, 2005.

CANDAU, V. M. A Didática em Questão. Editora Vozes: Petrópolis, 2012.

CERVO, A. L.; BERVIAN, P. A.; SILVA, R. da. Metodologia científica. 6. ed. São Paulo: Pearson Prentice Hall, 2007.

KENSKI, V. M. Tecnologias e ensino presencial e a distância. Campinas, SP: Papirus, 2003.

MORAN. José Manuel. Os novos espaços de atuação do professor com as tecnologias. Texto publicado nos anais do $12^{\circ}$ Endipe - Encontro Nacional de Didática e Prática de Ensino, in ROMANOWSKI, Joana Paulin et al (Orgs). Conhecimento local e conhecimento universal: Diversidade, mídias e tecnologias na educação. vol 2, Curitiba, Champagnat, 2004, páginas 245-253. Disponível em: < http://www.ufrgs.br/nucleoead/documentos/moranOsnovos.htm> Acesso em: 20 mai. 2016.

OLIVEIRA, E. G. Educação a distância na transição pragmática. Campinas, SP: Papirus, 2006. Coleção Magistério: Formação e Trabalho Pedagógico).

PACHECO, E. M.; MORIGI, V. (Org.). Ensino Técnico, Formação Profissional e Cidadania: a revolução da Educação Profissional e Tecnológica no Brasil. Porto Alegre: Tekne, 2012.

PRETI, O. Produção de material didático impresso: orientações técnicas e pedagógicas. Cuiabá: UAB/UFMT, 2010. 
SANTOS, Edméa. Educação online para além da EAD: um fenômeno da cibercultura. In: SILVA, Marco; PESCE, Lucila; ZUIN, Antônio (ORGs). Educação Online: cenário, formação e questões didático-metodológicas. Rio de Janeiro: Wak Editora, 2010.

SANTOS, Júlio. Mudanças Fundamentais na Educação. In: BATES (TONY) A.W. (Org). Educar na era digital: design, ensino e aprendizagem. São Paulo: Artesanato Educacional, 2016.

SOARES, E. M. D. S; VALENTINI, C. B.; RECH, J. Convivência e aprendizagem em ambientes virtuais: uma reflexão a partir da biologia do conhecer. Educação e Revista. v. 27, n. 3.Belo Horizonte dez.2011. Disponível em < http://dx.doi.org/10.1590/S0102-46982011000300003 >. Acesso em: 22 dez. 2017.

TORI, Romero. Educação sem distância: as tecnologias interativas na redução de distâncias em ensino e aprendizagem. 2. ed. São Paulo: Artesanato Educacional, 2017.

UEMA. Referenciais para os Cursos Técnicos da Universidade Estadual do Maranhão - UEMA: Rede e-Tec Brasil (Manual). Maranhão -São Luís: UEMA, 2013. 